\title{
Article \\ Modeling Strategy for 3-Wavelength (UV, Blue, Red) Controlled Photopolymerization: Part-II, Improved Conversion and Confinement in 3D-Printing
}

\author{
Jui-Teng Lin ${ }^{1}$, Da-Chuan Cheng ${ }^{2}$, Kuo-Ti Chen ${ }^{3}$, Yin-Chen Chiu ${ }^{4}$ and Hsia-Wei Liu 5,* \\ 1 New Vision, Inc. New Taipei City 242 Taiwan, ROC, jtlin55@gmail.com \\ 2 Department of Biomedical Imaging and Radiological Science, China Medical University, 404, Taiwan, \\ ROC, dccheng@mail.cmu.edu.tw \\ 3 Graduate Institute of Applied Science and Engineering, Fu Jen Catholic University, New Taipei City 242, \\ Taiwan, ROC, tony022199@msn.com \\ 4 Graduate Institute of Applied Science and Engineering, Fu Jen Catholic University, New Taipei City 242, \\ Taiwan, ROC, evan.yc.chiu@gmail.com \\ 5 Department of Life Science, Fu Jen Catholic University, New Taipei City 242, Taiwan, ROC \\ * Correspondence: 079336@gmail.com
}

\begin{abstract}
Detailed kinetics for a 3-wavelength photopolymerization confinement (PC) system is presented for both numerical solutions and analytic formulas. The dynamic profiles are simulated for oxygen, free radical, and conversion for various situations of: blue-light only, 2-light (red and UV), and 3-light (red, blue, UV). An effective PC requires two conditions: (i) a strong $\mathrm{N}$-inhibition for uncured regime with a low conversion (triggered by the UV-light); and (ii) a weak S-inhibition (oxygen-induced) for high conversion under the blue-light or blue and red-light initiation. Good PC candidates are governed by collective factors of: (i) the double ratio of light-intensity and initiatorconcentration, (ii) monomers rate-constant; and (iii) effective absorption constants at specific wavelength and initiators. A new reverse feature for the role of $\mathrm{N}$-inhibition on the blue-conversion is found. Higher oxygen concentration leads to a lower conversion, which could be enhanced by reducing the S-inhibition via a red or blue-light pre-irradiation, having a pre-irradiation time $\mathrm{T}_{\mathrm{P}}=200$ $\mathrm{s}$ for red-light only, and reduced to $150 \mathrm{~s}$, when both red and blue-light. System under UV-only leads a conversion lower than that of blue-only. However, conversion could be improved by the dual-light (blue and UV), and further enhanced by the pre-irradiation of red-light. The two competing factors, $\mathrm{N}$-inhibition and S-inhibition, could be independently and selectively tailored to achieve: (a) high conversion of blue-light (without UV-light), enhanced by red-light pre-irradiation for minimal S-inhibition; and (b) efficient PC initiated by UV-light produced N-inhibition for reduced confinement thickness and for high print speed.
\end{abstract}

Keywords: kinetic model; 3-wavelength; photopolymerization; spatial confirmation; additive manufacturing; $3 \mathrm{D}$ printing

\section{Introduction}

Various methods and materials for 3D printing and customized additive manufacturing (AM) have been reported [1-8]. Conventional photolithographic rapid prototyping is limited to a very thin layer of photo cured material having strong absorbing at a specific wavelength. Contemporary stereo lithographic devices use a single wavelength light to initiate polymerization patterned in a plane. However, the single-wavelength irradiation suffers the loss of polymerization confinement by accumulation of non-target light exposure [2-6]. To overcome this drawback, two-color (UV and blue light), direct-write photolithography was reported, in which the UV-light selectively results 
polymerization inhibition, concurrent with the blue-light photo-orthogonal, patterned irradiation employed to induce photopolymerization [9-11].

An idea AM system for efficient PC using a 3-wavelength (UV, red and/or blue light) requires the following conditions: (i) the photoinhibition light (UV) must yield significantly cease polymerization, while keeping sufficiently high polymerization rates produced by the initiation light (blue or red); (ii) a wide range of compatible monomers and co-initiators; (iii) the photoinhibition of free-radical chain-growth can be rapidly switched on and off by cycling the UV light; (iv) the formulated resins can be spatially confined using concurrent blue and UV irradiation; (v) rapid elimination of the inhibitor species in the dark, or after cessation of UV exposure; (vi) large polymerization inhibition depth adjacent to the projection window; and (vii) continuous part production at translation speeds of several hundred millimeters per hour. Above idea conditions allow for rapid, single-exposure fabrication of complex structures which can not be easily achieved by conventional single-wavelength methods.

Previously reported inhibition layers via oxygen inhibition are typically only tens of micrometers thick and thus it requires the use of low-viscosity resins or fabrication of objects with small cross sections. [6,7]. Single-wavelength, conventional and diffusion-reliant methods with a large inhibition thickness (IT) and high photoinitiation rates offer a continuous and rapid object printing [8-10]. However, they suffer the issues of separation resin reflow. In dual-wavelength systems, the IT may be reduced by decreasing irradiation intensity and thus increase the print speeds as polymerization proceeds closer to the projection window. For a given resin composition, the IT depends on the ratio of inhibitor to initiator absorbance, quantum yield of the radicals, reaction rates among the radicals and monomers, initiator, co-initiator and inhibitor, and the light intensity and dose (or exposure time).

Dual-wavelength photopolymerization confinement (PC) were reported in both parallel and perpendicular concurrent irradiation schemes $[10,11]$. The volumetric PC was achieved by inhibition depth controlled by varying the ratio UV and blue lights intensity, where print speeds of $2 \mathrm{~m} /$ hour have been achieved in a wide variety of resins including acrylates, methacrylates, and vinyl ethers. In addition, by varying the intensity of the light source on a per-pixel basis, the system can perform surface topographical patterning in a single exposure/layer with no stage translation [10]. In the perpendicular scheme, photopolymerizations were reported to confine in depth the region polymerized resin, in which two perpendicular blue and UV light, independently effect polymerization initiation and inhibition, respectively [11].

As reported by van der Laan et al [11], the effectiveness of a photoinhibitor is strongly monomer-dependent, which also requires: (i) a high conversion of blue-photoinitiation in the absence of the UV-active inhibitor; (ii) a strong chain termination with significant reduction of blue and UV conversion in the presence of UV-active inhibitor; and (iii) short induction time or rapid elimination of the inhibitor species in the dark (or absence of UV-light), such that the initiation-inhibition cycles may be switched on and off rapidly. Moreover, a short induction time may be achieved by high UV intensity or large inhibitor-concentration, and it also requires minimum impurity and oxygen which cause a delayed curing of the resin.

The monomer-dependence of a dual-wavelength PC was reported by van der Laan et al [11], in which different monomers have different $C=C$ bond rate constants $(K)$ under the exposure of blue, $\mathrm{UV}$ and blue+UV. For example, bisphenol ethoxylate diacrylate (BPAEDA) resins formulated with camphorquinone (CQ) and ethyl 4-(dimethylamino)benzoate (EDAB), for $0 \%$ butyl nitrite (BN), have a maximum conversion rate constant $\mathrm{Kmax}=0.675$ (at blue+UV), which is reduced to 0.0106 (for $1 \% \mathrm{BN}$ ). Therefore, it is a better candidate than trimethylolpropane triacrylate (TMPTA) which only has a 3 times reduction of Kmax.

We have previously reported the kinetics and modeling of a single-wavelength radicalmediated photopolymerization in single-initiator [12-14], two-initiator [15], two-component system [16]. Recently, we reported a modeling system for PC and introduced a new criterion for an effective PC based on a dual-wavelength (UV and blue) initiated photopolymerization, in which the UV-light serves as an inhibition for PC, named as N-inhibition. We have also reported a dual-wavelength (UV 
and red), in which the red-light serves as a reduction of singlet-oxygen inhibition, named as Sinhibition [16]. This study will extend our previous modeling to a 3-wavelength system consisting of $\mathrm{UV}$, blue and red light, such the two competing factors, $\mathrm{N}$-inhibition and S-inhibition, could be independently and selectively tailored to achieve: (i) high conversion of blue-light (without UVlight), enhanced by red-light pre-irradiation for minimal S-inhibition; and (ii) efficient PC initiated by UV-light produced N-inhibition for reduced confinement thickness for high print speed.

For the first time, this article will present the detailed kinetics for a 3-wavelength PC system. Analytical solutions for the kinetic equations and formulas will be derived. Then, we will show the numerical results for the oxygen, free radical and conversion profiles for various situations of: bluelight only, 2-light (red and UV), and 3-light (red, blue, UV). The role of oxygen, N-inhibition and Sinhibition are explored. Finally, we will discuss the inhibition-depth and strategy for accelerated printing speed, and the criterion for an efficient PC, which is governed by multiple factors.

\section{Materials and Methods}

\subsection{Photochemical Kinetic}

As shown by Fig. 1, a 3-wavelength (red, blue and UV light) radical-mediated system consists of 4-photoinitiator, A, B, C and D (as a donor). The blue-light conversion of monomer [M] could be enhanced by pre-irradiation of the red-light which reduces the oxygen-inhibition effect; and on the other hand, it could be reduced by the UV-light produced inhibitor [N], as a switch-off mechanism for controlled spatial confirmation.

The initiation radicals $\mathrm{R}$ and $[\mathrm{X}]$ crosslink with the monomer $[\mathrm{M}]$; whereas the inhibition radical $[N]$ reduces the active radical $R$, and thus the conversion efficacy. Also shown is the co-initiator (D) which reacts with the triplet state of $A\left(T^{*}\right)$ forming an intermediate radical $\left(R^{\prime}\right)$, and a propagating (reactive) radical ( $R$ ) leading to crosslinkers; terminations may be resulted by the interaction among $\mathrm{R}^{\prime}, \mathrm{R}$, and $[\mathrm{N}]$, and the bimolecular recombination term, $2 \mathrm{k}_{\mathrm{T}} \mathrm{R}^{\prime 2}$ and $2 \mathrm{k}_{\mathrm{T}} \mathrm{R}^{2}$; and another photosensitizer, $\mathrm{B}$, which serves as a photoinhibitor for the monomer conversion.

Example of 2-wavelength (blue and UV) system (without the red-light) for enhanced conversion by reducing the oxygen inhibition was reported by de Beer et al [10] and van der Laan et al [11], in which a blue $(470 \mathrm{~nm})$ and UV $(365 \mathrm{~nm})$ light were used for the photopolymerization of methacrylate formulated with camphorquinone (CQ) and ethyl 4-(dimethylamino)benzoate (EDAB), where CQ, as $\mathrm{A}$, butyl nitrite $(\mathrm{BN})$, as the UV-activated initiator (B), and EDAB (as a co-initiator, or donor $\mathrm{D}$ ). The photochemical decomposition of $\mathrm{BN}$ nitrites results in the formation of nitric oxide $(\mathrm{N})$, an efficient inhibitor of radical-mediated polymerizations, and alkoxide radical $(X)$ for extra polymerization initiation, beside the reactive radical $(\mathrm{R})$.

Example of 2-wavelength (red and UV) system (without the blue-light) for PC was reported by Childress et al [12], in which a monomer ( $\left.\mathrm{M}^{\prime}\right)$ of ethyl 4-(dimethylamino)benzoate (EDMAB) mixed by camphorquinone (CQ) to be sensitized by a red-light. Another monomer (M) of ethyl ether acrylate (DEGEEA), mixed by zinc 2,9,16,23-tetra-tert-butyl-29H,31H-phthalocyanine (ZnTTP), as an initiator under a UV-light, where ZnTTP and CQ have distinct absorption peak at UV-365 nm and red-635 $\mathrm{nm}$, respectively, and thus they can be independently excited by a UV and red light, respectively.

From the above two examples, one might have the option of using one single UV-light as an initiation of ZnTTP and also to produce an inhibitor $(\mathrm{N})$, such that only a dual-wavelength (red and UV) is needed for the dual-function of enhancement and confinement. However, the simultaneously irradiation of UV-light for initiation and inhibition has the drawback of losing the advantage offered by a 3-wavelength system, in which each of the 3-color could be turned on and off, sequentially and independently for both spatial and temporal control which could not be achieved by 2-wavelength.

Our red-blue-UV system could be extended to the following as far as these 3 wavelengths have minimal overlap in their absorbance spectra, such as: (i) red-light $(635 \mathrm{~nm})$, green $(532 \mathrm{~nm})$, and UVA $(365 \mathrm{~nm})$; (ii) near-IR $(750-810 \mathrm{~nm})$, red $(630-660 \mathrm{~nm})$, and near UV (365-405 nm); where most of these lights are available from the output of LED, and the associated photosensitizers (or photoinitiator). 


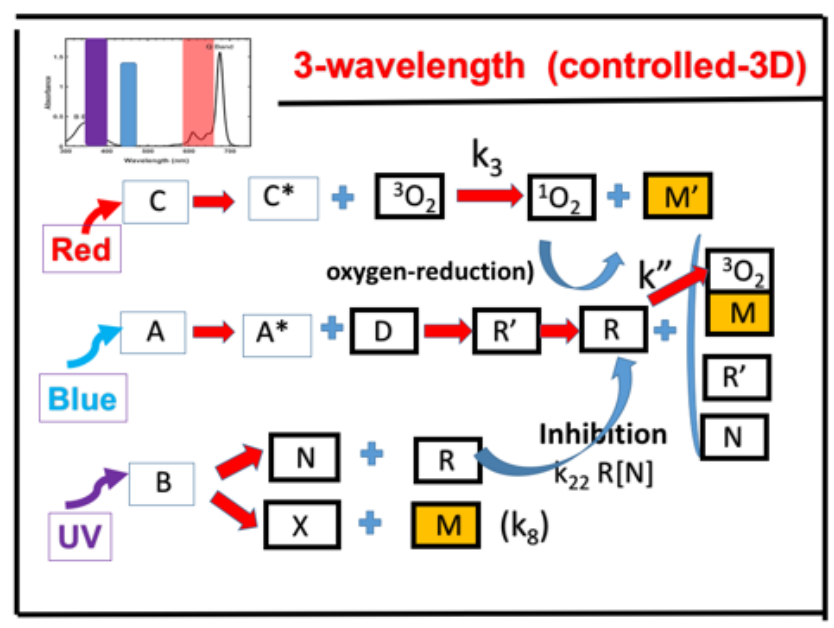

Figure 1. Schematics of photochemical pathways of a 3-wavelength photopolymerization; in which crosslinkers are formed via three pathways: the photoinitiator A (under a blue light), B (under a UV light), and oxygen-mediated $C$ (under a red light). The initiation radicals $R,\left[{ }^{1} \mathrm{O}_{2}\right]$ and $[\mathrm{X}]$ crosslink with the monomer $[\mathrm{M}]$; whereas the inhibition radical $[\mathrm{N}]$ reduces the active radical $\mathrm{R}$. Also shown is the co-initiator $(\mathrm{D})$ which reacts with the triplet state of $A\left(T^{*}\right)$ forming an intermediate radical $\left(\mathrm{R}^{\prime}\right)$ and a reactive radical $(R)$, leading to crosslinkers; terminations may be resulted by the interaction among $\mathrm{R}^{\prime}, \mathrm{R}$ and $[\mathrm{N}]$. The blue-light conversion could be enhanced by pre-irradiation of the red-light which reduces the oxygen-inhibition effect; whereas it could be reduced by the inhibitor $[\mathrm{N}]$, as a switch-off mechanism.

Short-hand notations for the concentration of various components are used: $[A],[B],[C],[D]$ for the ground state concentration of $\mathrm{A}, \mathrm{B}, \mathrm{C}, \mathrm{D}$, respectively; $\left[\mathrm{O}_{2}\right],[\mathrm{Y}]$ and $[\mathrm{X}]$ for the concentration of ground state oxygen, singlet oxygen radical, and inhibitor radical, respectively, and $\left[\mathrm{M}^{\prime}\right]$ and $[\mathrm{M}]$ are monomers. The kinetic equations for the 3 -wavelength and 5 radicals $\left(R^{\prime}, R,[N],[X],[Y]\right)$ system are derived, based on the schematics of Figure 1, as follows

$$
\begin{aligned}
& \frac{\partial[\mathrm{A}]}{\partial \mathrm{t}}=-\mathrm{gB}_{1}[\mathrm{D}][\mathrm{A}] \\
& \frac{\partial[\mathrm{B}]}{\partial \mathrm{t}}=-\mathrm{g}^{\prime} \mathrm{B}_{2}[\mathrm{M}][\mathrm{B}] \\
& \frac{\partial[\mathrm{C}]}{\partial \mathrm{t}}=-g^{\prime \prime} \mathrm{g}_{3}[\mathrm{C}] B_{3}\left[\mathrm{O}_{2}\right][\mathrm{C}] \\
& \frac{\partial[\mathrm{D}]}{\partial \mathrm{t}}=-\mathrm{gB}_{1}[\mathrm{D}][\mathrm{A}]+\mathrm{R}_{\mathrm{E}} \\
& \frac{\partial\left[O_{2}\right]}{\partial \mathrm{t}}=-\left(\mathrm{g}^{\prime \prime} \mathrm{B}_{3}[\mathrm{C}]+\mathrm{k}^{\prime \prime} \mathrm{R}\right)\left[O_{2}\right]+\mathrm{P} \\
& \frac{\partial[\mathrm{N}]}{\partial \mathrm{t}}=\mathrm{B}_{2}[\mathrm{~B}]-\mathrm{k}_{22} \mathrm{R}[\mathrm{N}] \\
& \frac{\partial[\mathrm{X}]}{\partial \mathrm{t}}=\mathrm{B}_{2}[\mathrm{~B}]-\left(\mathrm{k}_{6}+\mathrm{k}_{8}[\mathrm{M}]\right)[\mathrm{X}] \\
& \frac{\partial \mathrm{R}^{\prime}}{\partial \mathrm{t}}=\mathrm{gB}_{1}[\mathrm{D}][\mathrm{A}]-\left(2 \mathrm{k}_{\mathrm{T}} \mathrm{R}^{\prime}+\mathrm{k}_{12} \mathrm{R}\right) \mathrm{R}^{\prime} \\
& \frac{\partial \mathrm{R}}{\partial \mathrm{t}}=2 \mathrm{k}_{\mathrm{T}} \mathrm{R}^{\prime 2}-2 \mathrm{k}_{\mathrm{T}} \mathrm{R}^{2}-\left(k^{\prime}[\mathrm{M}]+\mathrm{k}_{12} \mathrm{R}^{\prime}+\mathrm{k}^{\prime \prime}\left[O_{2}\right]+\mathrm{k}_{22}[\mathrm{~N}]\right) \mathrm{R} \\
& \frac{\partial[\mathrm{M}]}{\partial \mathrm{t}}=-\left(\mathrm{k}_{8}[\mathrm{X}]+g^{\prime \prime} \mathrm{g}_{3} B_{3}[C]\left[O_{2}\right]+\mathrm{k}^{\prime} \mathrm{R}\right)[\mathrm{M}]
\end{aligned}
$$

where $\mathrm{B}_{1}=\mathrm{b}_{1} \mathrm{I}_{1}(\mathrm{z}, \mathrm{t}), \mathrm{B}_{2}=\mathrm{b}_{2} \mathrm{I}_{2}(\mathrm{z}, \mathrm{t}) \mathrm{I}_{3}(\mathrm{z}, \mathrm{t}) / \mathrm{I}_{30}, \mathrm{~B}_{3}=\left(\mathrm{b}_{3} / \mathrm{b}_{2}\right) \mathrm{B}_{2} ; \mathrm{g}=1 /\left(\mathrm{k}_{57}+[\mathrm{D}]\right) ; \mathrm{g}^{\prime}=1 /\left(\mathrm{k}_{68}+[\mathrm{M}]\right), \mathrm{g}^{\prime \prime}=1 /\left(\mathrm{k}_{63}+\right.$ $\left.\mathrm{k}^{\prime \prime}\left[\mathrm{O}_{2}\right]\right), \mathrm{g}_{3}=1 /\left(\mathrm{k}_{63}+\mathrm{k}_{13}[\mathrm{C}]+\mathrm{k}_{83}\left[\mathrm{M}^{\prime}\right]\right)$; where $\mathrm{k}_{\mathrm{ij}}=\left(\mathrm{k}_{\mathrm{i}} / \mathrm{k}_{\mathrm{j}}\right)$. $\mathrm{R}_{\mathrm{E}}$ is the $[\mathrm{D}]$ regeneration term given by $\mathrm{R}_{\mathrm{E}}=$ $k^{\prime \prime} R\left[O_{2}\right]+k_{22}[N] R+2 k_{T} R^{2} . b_{j}=83.6 a_{j} q_{j} w_{j}$; $a_{j}$ is the extinction coefficient for $A, B$ and $C$ (with $j=1,2,3$ ); the light wavelength (in cm), w1 for the blue (at $470 \mathrm{~nm}$ ), w2 for UV (at $365 \mathrm{~nm}$ ), w3 for red (at $635 \mathrm{~nm}$ ) and light intensity $\mathrm{I}_{j}(\mathrm{z}, \mathrm{t})$ in $\mathrm{mW} / \mathrm{cm}^{2} ; \mathrm{q}_{\mathrm{j}}$ is the quantum yields of the $[\mathrm{A}]$ triplet state and PB radical $[13,15]$. 
All the reaction rate constants are defined by the associated coupling terms. For examples, in Eq. (7), $\mathrm{k}^{\prime}$ is for the reaction of monomer and radical $\mathrm{R}$, which has a relaxation rate $\mathrm{k}_{5} ; \mathrm{k}_{12}$ is for the radical interaction of $\mathrm{R}^{\prime}$ and $\mathrm{R}$, and both have a bimolecular termination rate of $\mathrm{k}_{\mathrm{T}}$; More detail derivation and definition of rate constants in $g$ and $g^{\prime}$, have been previously published $[13,16]$.

Using the quasi-steady-state conditions of [13] $\mathrm{d}[\mathrm{N}] / \mathrm{dt}=\mathrm{d}[\mathrm{X}] / \mathrm{dt}=\mathrm{d}\left[\mathrm{R}^{\prime}\right] / \mathrm{dt}=0$, we obtain steadystate radicals given by $[N]=B_{2}[B] /\left(k_{22} R\right),[X]=g^{\prime} B_{2}[B] / k_{8}$. For analytic solutions, we consider the situation that $\left.\mathrm{k}_{57}<<[\mathrm{D}], \mathrm{k}_{68}<<[\mathrm{M}], \mathrm{k}_{63}<<\mathrm{k}^{\prime \prime}\left[\mathrm{O}_{2}\right],\left(\mathrm{k}_{63}+\mathrm{M}\right)<<\mathrm{k}_{13}[\mathrm{C}]\right)$, such that $\mathrm{g}[\mathrm{D}]=\mathrm{g}^{\prime}[\mathrm{M}]=\mathrm{g}_{3}[\mathrm{C}]=\mathrm{g}^{\prime \prime}\left[\mathrm{O}_{2}\right]=1$; and Eq. (1) to (10) are simplified to

$$
\begin{aligned}
& \frac{\partial[\mathrm{A}]}{\partial \mathrm{t}}=-\mathrm{B}_{1}[\mathrm{~A}] \\
& \frac{\partial[\mathrm{B}]}{\partial \mathrm{t}}=-\mathrm{B}_{2}[\mathrm{~B}] \\
& \frac{\partial[\mathrm{C}]}{\partial \mathrm{t}}=-\mathrm{B}_{3}[\mathrm{C}] \\
& \frac{\partial\left[\mathrm{O}_{2}\right]}{\partial \mathrm{t}}=-B_{3}[\mathrm{C}]-\mathrm{k} " \mathrm{R}\left[O_{2}\right]+\mathrm{P} \\
& \frac{\partial[\mathrm{M}]}{\partial \mathrm{t}}=-\mathrm{R}_{\mathrm{T}}[\mathrm{M}] \\
& \mathrm{R}_{\mathrm{T}}=\mathrm{B}_{2}[\mathrm{~B}]+\mathrm{B}_{3}[\mathrm{C}]+\mathrm{k}^{\prime} \mathrm{R}
\end{aligned}
$$

Where $R_{T}$ is a total rate constant which consists of three crosslink components attributed from the radicals $[X]$, singlet-oxygen, and free radical (R). Furthermore, the steady-state radicals, $R^{\prime}$ and $R$, are given by, where we keep the $g[D]$ term for more general case,

$$
\begin{aligned}
& 2 \mathrm{k}_{\mathrm{T}} \mathrm{R}^{\prime 2}+\mathrm{k}_{12} \mathrm{R}^{\prime}-\mathrm{g}[\mathrm{D}] \mathrm{B}_{1}[\mathrm{~A}]=0 \\
& 2 \mathrm{k}_{\mathrm{T}} \mathrm{R}^{2}+\left(k^{\prime}[\mathrm{M}]+\mathrm{k}^{\prime \prime}\left[O_{2}\right]+\mathrm{k}_{12} \mathrm{R}^{\prime}\right) \mathrm{R}-\left(2 \mathrm{k}_{\mathrm{T}} \mathrm{R}^{\prime 2}-\mathrm{B}_{2}[\mathrm{~B}]\right)=0
\end{aligned}
$$

Solving for Eq. (11) and (12), we obtain [16]

$$
\begin{aligned}
& R=\left(\frac{1}{4 \mathrm{k}_{\mathrm{T}}}\right)\left[-G+\sqrt{G^{2}+8 \mathrm{k}_{\mathrm{T}} \mathrm{H}}\right] \\
& \mathrm{H}=\mathrm{g}[\mathrm{D}] \mathrm{B}_{1}[\mathrm{~A}]-\mathrm{B}_{2}[\mathrm{~B}]
\end{aligned}
$$

where $G=k^{\prime}[M]+k^{\prime \prime}\left[\mathrm{O}_{2}\right]+2 k_{12} R^{\prime}$. Eq. (19) may be further approximated to $\mathrm{R}=\left(0.5 \mathrm{H} / \mathrm{k}_{\mathrm{T}}\right)^{0.5}$ $\left(\mathrm{k}^{\prime}[\mathrm{M}]+\mathrm{k}^{\prime \prime}\left[\mathrm{O}_{2}\right]\right)(1-\mathrm{d})$, with $\mathrm{d}=0.5 \mathrm{G}^{2} /\left(8 \mathrm{k}_{\mathrm{T}} \mathrm{H}\right)$, for $2 \mathrm{k}_{12} \mathrm{R}^{\prime}<<\mathrm{k}^{\prime}[\mathrm{M}]$, which shows that $\mathrm{R}$ and efficacy, are increasing function of $\mathrm{H}$. The balance point of inhibition depth is defined by when $\mathrm{R}=0, \mathrm{or} 8 \mathrm{k}_{\mathrm{T}} \mathrm{H}=0$, or $\mathrm{B}_{1}[\mathrm{~A}]=\mathrm{B}_{2}[\mathrm{~B}]$, for $\mathrm{g}[\mathrm{D}]=1$, in which the $[\mathrm{A}]$ initiated radical $(\mathrm{R})$ is completely inhibited/consumed by the $[\mathrm{B}]$ radical, $[N]$, and thus the total rate function $\mathrm{R}_{\mathrm{T}}$ of Eq. (16) is by the first two terms, $\mathrm{B}_{2}[\mathrm{~B}]+\mathrm{B}_{3}[\mathrm{C}]$. We will have more discussion later.

The dynamic light intensity of blue ( $\left.\mathrm{I}_{1}\right)$ and UV $\left(\mathrm{I}_{2}\right)$ are given by, when they are applied to the resin orthogonally and separately [16,17]

$$
\begin{aligned}
& I_{j}(z, t)=I_{j 0} \exp \left[-A_{j} z\right] \\
& A_{j}(\mathrm{z}, \mathrm{t})=2.3\left(a_{j} C_{j 0}+Q_{j}\right)-A_{\mathrm{j} 1} \mathrm{t}
\end{aligned}
$$

where $a_{j}$ is the extinction coefficients of [A] (for $j=1$ ) and [B] (for $j=2$ ) and their photolysis products, respectively; $\mathrm{Q}_{j}$ is the absorption coefficient of the monomer at the blue and UV wavelength. Most previous modeling [8-13] assumed a constant $C(z, t)$ in Eq. (2.b). Our analytic formulas in this article will use a time-average of $A(z, t)$ to count for the dynamic of light intensity due to PA and PB depletions. Accurate solutions of Eq. (1) and (8) require numerical simulations (to be shown later). For analytic formulas, we will use approximated analytic formulas for the light intensity and the PI and PE concentration and the expressive closed forms of $I_{j}(z, t)$ and $C_{j}(z, t)$ allow us to solve for the first-order and second-order solutions of $\mathrm{R},[\mathrm{M}]$ and the conversion efficacy.

\subsection{Analytic Formulas for Efficacy}

The monomer conversion efficacy for a bimolecular termination process is given by CEFF $=1$ $[\mathrm{M}] /[\mathrm{M}]_{0}=1-\exp (-\mathrm{S})$, with $[\mathrm{M}]_{0}$ being the initial monomer concentration, and the S-function is given 
by the time integral of the total rate factor $\mathrm{R}_{\mathrm{T}}$ given by Eq. (16). Solutions of Eq. (11) to (15) are available by the approximated analytic formulas for $\mathrm{I}_{j}(\mathrm{z}, \mathrm{t})$ and $\mathrm{C}_{\mathrm{j}}(\mathrm{z}, \mathrm{t})$, with $\mathrm{j}=1,2,3$, for $[\mathrm{A}],[\mathrm{B}]$ and $[\mathrm{C}]$, as follow $[13,15]$

$$
\begin{aligned}
& I_{j}(z, t)=I_{j 0} \exp \left[-A_{j} z\right] \\
& {[\mathrm{A}](z, t)=[A]_{0} \exp \left[-B^{\prime}{ }_{j} t\right]} \\
& {[\mathrm{B}](z, t)=[B]_{0} \exp \left[-B^{\prime}{ }_{j} t\right]} \\
& {[C](z, t)=[C]_{0} \exp \left[-B_{j}^{\prime} t\right]}
\end{aligned}
$$

where $B^{\prime}{ }_{j}=b_{j} I_{j 0} \exp \left(-A_{j}{ }^{\prime} z\right), A_{j 1}=2.3\left(a_{j}-b_{j}^{\prime}\right) C_{j 0} I_{j o} b_{j} Z$, with $A_{j}{ }^{\prime}$ is the time-averaged absorption given by $A j^{\prime}=1.15\left(a_{j}+b^{\prime} j\right)+2.3 Q_{j}, b j^{\prime}$ is the extinction coefficient of the photolysis products. We note that the $-A_{j 1}$ term represents the decrease of $A_{j}^{\prime}$, or increase of light intensity due to concentration depletions of $[\mathrm{A}],[\mathrm{B}]$ and $[\mathrm{C}]$.

Using Eq. (25) to (28) and Eq. (11) for the total rate faction, $\mathrm{R}_{\mathrm{T}}$, we solve for Eq. (15) to obtain the conversion efficacy given by $C_{E F F}=1-[M] /[M] 0=1-\exp (-S)$, with $S$ is the time integral of $R_{T}$, which requires a numerical integration, in general. For analytic solutions, two cases are considered. For $\mathrm{gB}_{\mathrm{j}} \mathrm{C}_{\mathrm{j}}<<\mathrm{k}^{\prime} \mathrm{R}$, case (i) $\mathrm{H}>>\mathrm{G}, \mathrm{k}^{\prime} \mathrm{R}=\mathrm{KH}^{0.5}$, with $\mathrm{K}=0.5 \mathrm{k}^{\prime} / \mathrm{k}_{\mathrm{T}}{ }^{0.5}$; case (ii) $\mathrm{H}<<\mathrm{G}, \mathrm{k}^{\prime} \mathrm{R}=\mathrm{KH}^{0.5} / \mathrm{G}$; where $\mathrm{H}^{0.5}$ may be further reduced to $\mathrm{H}^{0.5}=\left(\mathrm{B}_{1}[\mathrm{~A}]\right)^{0.5}-0.5\left(\mathrm{~B}_{2}[\mathrm{~B}]\right) /\left(\mathrm{B}_{1}[\mathrm{~A}]\right)^{0.5}$, for $\left(\mathrm{B}_{2}\left[\mathrm{~B}_{3}\right]<<\left(\mathrm{B}_{1}[\mathrm{~A}]\right)\right.$, and $\mathrm{g}[\mathrm{C}]=1$, for $\mathrm{k}=\mathrm{k}_{3} / \mathrm{k}=1$.

In case (i), $\mathrm{C}_{\mathrm{EFF}}=1-[\mathrm{M}] /[\mathrm{M}] \mathrm{0}=1-\exp (-\mathrm{S})$, with $\mathrm{S}$-function is given by

$$
\begin{aligned}
& S=S_{1}+S_{2}+S_{3} \\
& S_{1}=D_{20} E_{11} \\
& S_{3}=D_{30} E_{33} \\
& S_{2}=K \sqrt{D_{10}}\left[E_{11}-0.5\left(D_{20} / D_{10}\right) E_{12}\right] \\
& E_{11}=\left[1-\exp \left(-G_{32} t\right)\right] / G_{32} \\
& E_{33}=\left[1-\exp \left(-G_{33} t\right)\right] / G_{33} \\
& E_{21}=\left[1-\exp \left(-G_{31} t\right)\right] / G_{31} \\
& E_{22}=\left[1-\exp \left[-\left(G_{32}-G_{31}\right) t\right] /\left(G_{32}-G_{31}\right)\right.
\end{aligned}
$$

where initial values: $D_{j 0}=B_{j 0} X_{j}, \quad G_{3 j}=0.5\left(B_{j 0}-A^{\prime}{ }_{1 j}\right)$, with $\quad B_{j 0}=b_{j} I_{j 0} C_{j 0}, \quad X_{j}=\exp \left(-A^{\prime}{ }_{j} z\right)$, $A_{j}^{\prime}=1.15\left(a_{j}+b_{j}\right) C_{j 0}+2.3 Q_{j}$, is a mean value of $A_{j}(z, t)$, we have have re-defined $C_{j}$ with $j=1,2,3$ for $[A],[B]$, [C].

For case (ii), and for $\mathrm{k}^{\prime}[\mathrm{M}]<<\mathrm{k}^{\prime} \mathrm{R}, \mathrm{k}^{\prime} \mathrm{R}=\mathrm{K}^{\prime} \mathrm{H} /[\mathrm{M}], \mathrm{K}^{\prime}=0.5 / \mathrm{kT}^{0.5}$, Eq. (15) becomes

$\frac{\partial[\mathrm{M}]}{\partial \mathrm{t}}=-\mathrm{K}^{\prime} \mathrm{H}(\mathrm{t})$

Therefore, the efficacy $\mathrm{C}_{\mathrm{EFF}}=1-[\mathrm{M}] /[\mathrm{M}]_{0}$ is given by the time integral of $\mathrm{H}(\mathrm{t}) /[\mathrm{M}]_{0}$, or

$C_{E F F}=K^{\prime} S /[M]_{0}$

with $S$ given by Eq. (29).

The steady-state of Eq. (28) and (29) are given by when $E_{11}=1 / G_{31}, E_{12}=1 /\left(G_{32}-G_{31}\right)$, whereas transient state is given by $\mathrm{E}_{11}=\mathrm{E}_{12}=\mathrm{t}$. Therefore, the inhibition effect given by the second term of $\mathrm{Eq}$. (32) is proportional to $\mathrm{B}_{20} /\left(\mathrm{B}_{10}\right)^{0.5} /\left(\mathrm{G}_{32}-\mathrm{G}_{31}\right)$, with $\mathrm{B}_{\mathrm{j} 0}=\mathrm{b}_{\mathrm{j}} \mathrm{I}_{0} \mathrm{C}_{\mathrm{j} 0}$, for steady-state; and $\left[\mathrm{tB}_{20} /\left(\mathrm{B}_{10}\right)^{0.5}\right]$ for transient state. Numerical data will be shown later. We also note that for a given $B_{1} C_{1}$, the radical $R$ is a decreasing function of the ratio of $R_{A B}=\left(B_{2} C_{2}\right) /\left(B_{1} C_{1}\right)^{0.5}$. Therefore, same $R_{A B}$ reaches the same efficacy.

We also note that the total rate function of Eq. (16) may be further expressed as

$$
\begin{aligned}
& \mathrm{R}_{\mathrm{T}}=\mathrm{G}_{1}-\mathrm{G}_{2} \\
& \mathrm{G}_{1}=\mathrm{g}[\mathrm{D}] \mathrm{B}_{1}[\mathrm{~A}]+\mathrm{B}_{3}[\mathrm{C}] \\
& \left.\mathrm{G}_{2}=(K-1)\right] \mathrm{B}_{2}[\mathrm{~B}]+\mathrm{k}^{\prime}\left(\mathrm{k}^{\prime}[\mathrm{M}]+\mathrm{k}^{\prime \prime}\left[\mathrm{O}_{2}\right]\right.
\end{aligned}
$$

which shows the following features: (i) $R_{T}$ is an increasing function of $G_{1}$, or $B_{1}[A]$ and $B_{3}[C]$; but decreasing function of $\mathrm{G}_{2}$, or $\mathrm{B}_{2}[\mathrm{~B}]$ and $\mathrm{k}^{\prime \prime}\left[\mathrm{O}_{2}\right]$; (ii) for significant confirmation, one requires a small $\mathrm{R}_{\mathrm{T}}=\mathrm{G}_{1}-\mathrm{G}_{2}$,or the significant reduction of conversion reduction by the coinitiator $[\mathrm{B}]$, or the presence of oxygen $\left[\mathrm{O}_{2}\right]$; (iii) as a good switcher, one also requires reduced oxygen inhibition via [C], (when $[B]$ is absent) for high conversion; but requires large [B] for a low conversion. Above features will be numerically shown later. 


\subsection{The Inhibition Depth}

Polymerization inhibition depth $(\mathrm{ZH})$ adjacent to the projection window is a critical parameter for continuous stereolithographic fabrication [12, 18-21]. ZH defines the vertical distance into the resin from the transparent window in which no polymerization occurs, may be calculated by the balance point of initiation and inhibition rate, or when $\mathrm{R}=0$, or $\mathrm{H}=0$. From Equation (20) and (21), we obtain [17]

$$
Z_{H}=\frac{1}{\mathrm{~A}_{2}-\mathrm{A}_{1}} \ln \left(\frac{\mathrm{B}_{20}[\mathrm{~B}]_{0}}{g \mathrm{~B}_{10}[\mathrm{~A}]_{0} \mathrm{D}_{0}}\right)
$$

where $B_{j 0}=b_{j} I_{j 0}$. We note that Equation (42) defines an inhibition coefficient defined by $\beta=$ $\left(b_{2} / b_{1}\right)[B]_{0} /\left(g[A]_{0} D_{0}\right)$, which depends on a multifactor and rate constants related by $g=1 /\left(k_{57}+k[C]\right)$. Our formula is more general than that of de Beer et al. [10], which is our special case when $[\mathrm{B}]_{0}=$ $\mathrm{g}[\mathrm{A}]_{0} \mathrm{D}_{0}$, such that Equation (25) reduces to Equation (1) of de Beer et al. [10]: $\mathrm{ZH}^{=}\left(1 /\left(\mathrm{A}_{2}-\right.\right.$ $\left.\mathrm{A}_{1}\right) \ln \left[\beta \mathrm{I}_{20} / \mathrm{I}_{10}\right]$, with with $\beta=\mathrm{b}_{2} / \mathrm{b}_{1}$. We note that $\mathrm{b}_{\mathrm{j}}=83.6 \mathrm{a}_{j} \mathrm{q}_{\mathrm{j}} \mathrm{w}_{\mathrm{j}}$, which is defined by the extinction coefficient for $A, B$ and $D$ (with $j=1,2,3$ ); the light wavelength, $w_{1}$ for the blue (at $470 \mathrm{~nm}$ ) and $\mathrm{w}_{2}$ for UV (at $365 \mathrm{~nm}$ ) and the quantum yields $\left(\mathrm{q}_{\mathrm{j}}\right)$. Moreover, in our more general formula, $\beta$ is also proportional to $1 / \mathrm{g}=\mathrm{k}_{57}+\mathrm{k}[\mathrm{C}]$, defined by the rate constants of $\mathrm{k}_{57}$ and $\mathrm{k}=\mathrm{k}_{3} / 7$.

A minimum intensity ratio of $\mathrm{UV}$ and blue light, $\mathrm{Rmin}=\left(\mathrm{I}_{20} / \mathrm{I}_{10}\right)_{\text {crit }}$ defined by which initiation and inhibition rates are balanced to generate an inhibition depth, $\mathrm{zH}=0$ in Equation (42), and can be calculated by when $\mathrm{Rmin}=1 / \beta^{\prime}=\mathrm{g}[\mathrm{A}]_{0} \mathrm{D}_{0} /\left[\left(\mathrm{b}_{2} / \mathrm{b}_{1}\right)[\mathrm{B}]_{0}\right]$, which is dependent on resin composition ratios and rate constants. de Beer et al. reported $\beta^{\prime}=1$, in a TMPTA-based system [10].

\subsection{The Print Speed}

Based on Equation (22), the maximum print speed (Smax) as defined by de Beer et al. [10], when the dose difference of blue light and UV light equals to a critical value $\left(\mathrm{E}^{*}\right)$, and $\mathrm{B}_{1}=\beta \mathrm{B}_{2}$, we obtain a similar formula:

$$
S_{\max }=\left[I_{10} /[A]_{0}-\beta^{\prime} I_{20} /[B]_{0}\right] /\left(\left(b_{1} E^{*}\right)\right.
$$

which, however, has a more complex function $\beta^{\prime}=[\mathrm{B}]_{0} /\left(\mathrm{g}[\mathrm{A}]_{0} \mathrm{D}_{0}\right)$, than the simplified function of de Beer et al. [10], with $\beta=b_{2} / b_{1}$.

Previously reported inhibition layers resulting from oxygen inhibition are typically only tens of micrometers thick. Therefore, its applications are limited to low-viscosity resins or fabrication of objects with small cross sections. In the dual-wavelength system, high rates are achievable by adjusted inhibiting (UV) intensity to maintain a constant inhibition depth. As shown by Eq. (41), high print speed requires a small $\beta^{\prime} \mathrm{I}_{20} /[\mathrm{B}]_{0}$, or small $\mathrm{zH}$, by decreasing $\beta \mathrm{I}_{20} / \mathrm{I}_{10}$, as shown by Eq. (40).

\subsection{The Curing Depth}

The curing depth of the blue-light is defined by when the blue light dose, I10t, is larger than a threshold value of $\mathrm{E}_{\mathrm{TH}}$. Using the time integral of Equation (23) with neglected Ait, we obtain [16]

$$
Z_{C}=\frac{1}{A_{1}} \ln \left(\frac{I_{10} t}{E_{T H}}\right)
$$

\section{Results and Discussion}

Numerical results based on Eq. (11) to (20) are shown as follows. We will first show the conversion of blue-light only; 2-light (red and UV), and 3-light (red, blue, UV). We will explore the role of oxygen and the role of the inhibitor concentration [B]. Finally, we show the role of red- 
initiator [C], in the presence of both blue and UV light. For comprehensive analysis, we define two types of inhibitions which reduce the free radical (R) and conversion: (i) the co-initiator(B) and UVlight induced $\mathrm{N}$-inhibition (due to the $[\mathrm{N}]$ radical); and (ii) the oxygen-mediated singlet-oxygeninhibition, S-inhibition. An effective photopolymerization confinement (PC) requires a strong $\mathrm{N}$ inhibition (for a low conversion), but a weak S-inhibition (for high conversion).

Figure 2 shows the oxygen profiles under the irradiation of (i) red-light only, and (ii) blue and red light, in the absence of UV-light (or $\mathrm{B}_{2}=0$ ), for various initial oxygen concentration of $\left[\mathrm{O}_{2}\right]_{0}$, where oxygen depletion under a red-light only is accelerated by the blue and red-light. Figure 2 can be used to find a pre-irradiation time $\left(\mathrm{T}_{\mathrm{P}}\right)$ to improve the conversion. For example, given an initial oxygen concentration of $2 \mathrm{mg} / \mathrm{L}$, to obtain a reduced concentration of $1.0 \mathrm{mg} / \mathrm{L}$ and $0.5 \mathrm{mg} / \mathrm{L}$, one requires $T_{R}=200$ and $900 \mathrm{~s}$, respectively, when only red-light is used (left Figure); however, $T_{R}$ reduce to 150 and $320 \mathrm{~s}$, respectively, when both red and blue-light are used (right Figure).

Figure 3 shows the role of oxygen on the conversion profiles under the irradiation of blue-light only, in which conversion is a decreasing function of oxygen due to the S-inhibition. Conversion is saturated when oxygen is completely depleted. Therefore, higher initial oxygen leads to larger Sinhibition, or reduction of the free radical (R), thus a lower conversion, as also predicted by Eq. (27).

Figure 4 shows the role of co-initiator (B) on the conversion profiles and H-function, where higher concentration, $[\mathrm{B}]_{0}$, produces more inhibitor $[\mathrm{N}]$, or a strong $\mathrm{N}$-inhibition, thus leads to a lower conversion. However, there is a transition/reversion point when $\mathrm{H}=0$, (or $\left.[\mathrm{B}]_{0}=1.2\right)$, i.e., reverse feature (as shown by the dashed-curve) is found that higher [B] leads to higher conversion, resulted from the first term of the total rate $\mathrm{R}_{\mathrm{T}}$, as predicted by our analytic formula, Eq. (16), (19) and (37). This is one of the new findings of this modeling study, which, however, requires further experimental justification.

Figure 5 shows that the conversion is a deceasing function of the oxygen and the co-initiator concentration, $[\mathrm{B}]_{0}$, or the inhibitor $[\mathrm{N}]$. For an effective confinement, one requires a strong $\mathrm{N}$ inhibition (or a high $[\mathrm{B}]_{0}$ ), but also a weak S-inhibition (or a low $\left[\mathrm{O}_{2}\right]_{0}$ ). Figure 5 demonstrates that higher $\left[\mathrm{O}_{2}\right]_{0}$ has a less effective confinement. Therefore, a red-light pre-irradiation to reduce the where the S-inhibition is required, specially for the case of thin polymers having strong oxygen diffusion.

Figure 6 shows the conversion profiles, under various the irradiation conditions, where the UVonly leads to the lowest conversion, lower than the blue-only, but could be enhanced by the blueand-UV light. Similar features are found for the oxygen profiles which are also shown by Figure 6.

Figure 7 shows the conversion profiles, under of 2-light (blue and red) and 3-light (blue, red and UV), in the presence of oxygen, where significant drop of conversion (required condition for an efficient PC) occurs in the presence of UV-light (or 3-light case) and a high N-inhibition concentration, $[\mathrm{B}]_{0}$. Figure 7 also shows that without the UV-light, the conversions are rather high for all ranges of oxygen, and they are a poor PC. Figure 8 shows the free radical profiles (R) associate with Figure 7 , for 2-light (without UV); and 3-light (with UV), where the time integral of the R-profile gives the conversion due to blue-light induced free radical (R), as also shown by Eq. (15), and (16).

Figure 9 shows the role of the co-initiator $(C)$, where higher concentration $[C]_{0}$ leads to a higher conversion due to a higher reduction of oxygen, and the S-inhibition, as also predicted by Eq. (39). Therefore, for a system having a lower conversion (in the presence of oxygen), the red-light preirradiation step to reduce S-inhibition is required. 

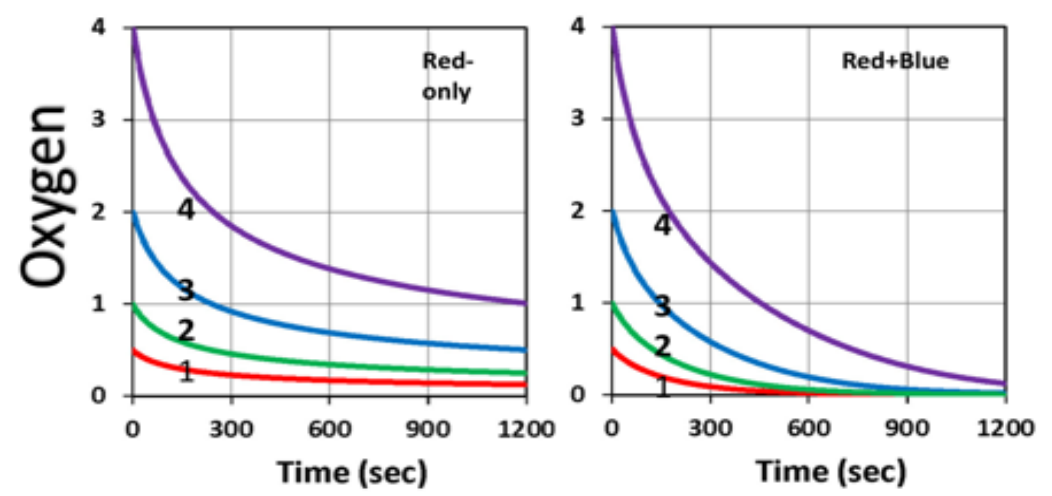

Figure 2. Oxygen profiles under the irradiation of red-light only (left); blue and red light (right); but in the absence of UV-light (or $\mathrm{B}_{2}=0$ ), for various initial oxygen concentration of $\left[\mathrm{O}_{2}\right]_{0}=(0.5,1.0,2.0$, $4.0) \%$, for curve $(1,2,3,4) ;$ and $[\mathrm{A}]_{0}=[\mathrm{B}]_{0}=1 \% ; \mathrm{B}_{1}=\mathrm{B}_{3}=0.05(1 / \mathrm{s} / \%) ;$ and rate constants $\left(\mathrm{k}, \mathrm{k}^{\prime}, \mathrm{k}^{\prime \prime}, \mathrm{kT}\right)=(8,1,0.1,0.5)\left((1 / \mathrm{s})\right.$. profiles of blue-light (without UV-light) for (left Figure) $\mathrm{C}_{10}=(0.05,0.1$, $0.2,0.4) \%$, for curve $(1,2,3,4)$, for fixed $b_{1}=0.1$; and (right Figure) $b_{1}=(0.015,0.05,0.15,0.5)$, for fixed $\mathrm{C}_{10}=0.2 \%$; for $\mathrm{C}_{30}=0.5 \%,[\mathrm{M}]_{0}=0.2 \%, \mathrm{k}^{\prime}=1.0, \mathrm{k}_{\mathrm{T}}=0.5, \mathrm{k}_{57}=\left(\mathrm{k}_{5} / \mathrm{k}_{7}\right)=\mathrm{k}_{68}=\left(\mathrm{k}_{6} / \mathrm{k}_{8}\right)=\mathrm{k}^{\prime \prime}=35(1 / \mathrm{s})$.

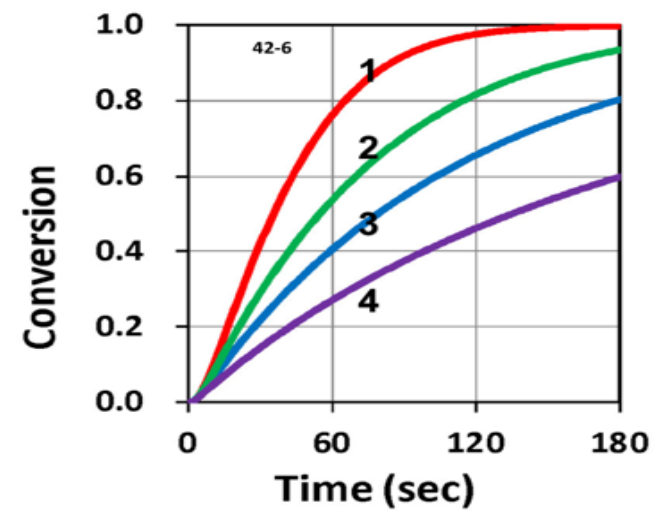

Figure 3. Conversion profiles under irradiation of blue-light only (with $\mathrm{B}_{2}=\mathrm{B}_{3}=0$ ), for various initial oxygen concentration of $\left[\mathrm{O}_{2}\right]_{0}=(0,1.0,2.0,4.0) \mathrm{mg} / \mathrm{L}$, for curve $(1,2,3,4)$.

same as Figure 2 but for various $\mathrm{k}^{\prime}=(1.0,0.3,0.19)$, for curves $(1,2,3)$, for fixed $\mathrm{C}_{10}=0.2 \%$, and adjusted $\mathrm{b}_{1}=(0.15,0.05,0.05)$ to fit the measured data of de Beer et al. [10].
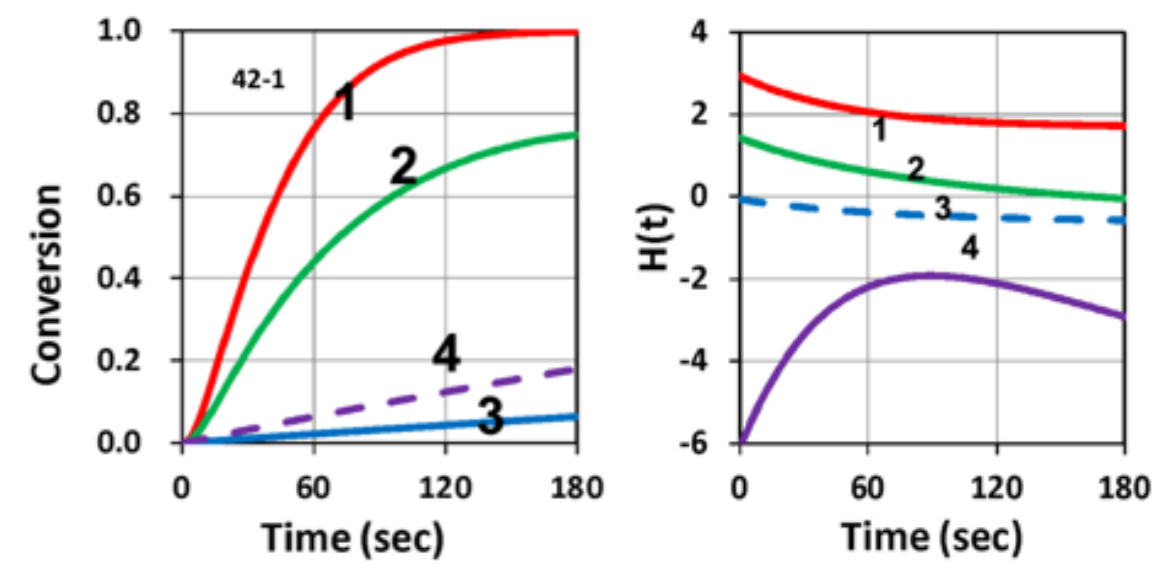
Figure 4. Conversion profiles (left) and $\mathrm{H}$-function (right), under the irradiation of 2-light (blue and $\mathrm{UV})$, without oxygen $\left(\left[\mathrm{O}_{2}\right]_{0}=0\right)$ or the red-light $\left(\mathrm{B}_{3}=0\right)$, for various initial concentration of $[\mathrm{B}]_{0}=(0,0.5$, $1.0,3.0) 1 \%$, for curves $(1,2,3,4)$; and for $\left(\mathrm{B}_{1}, \mathrm{~B}_{2}\right)=(0.05,0.003)$, and $[\mathrm{A}]_{0}=1 \%$.
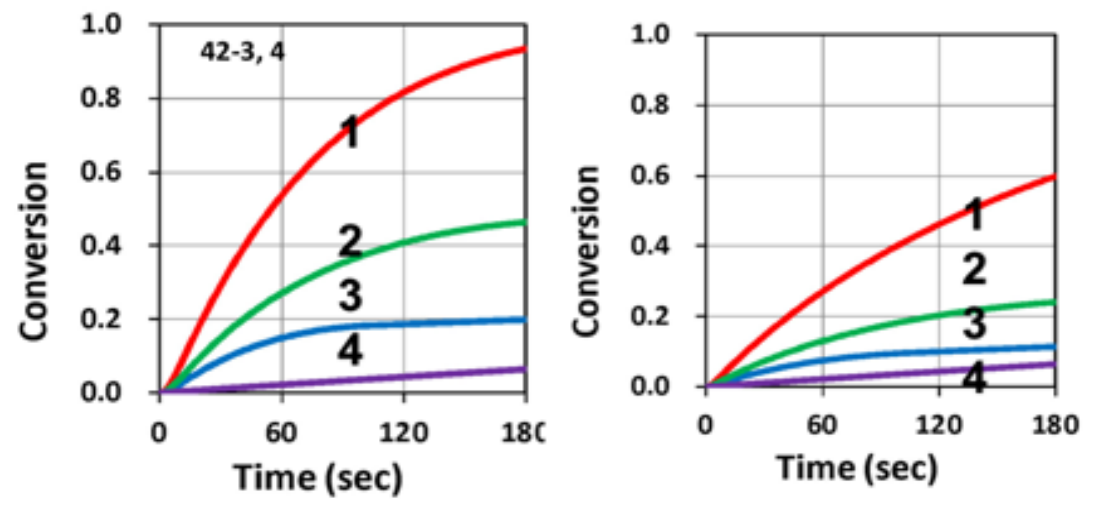

Figure 5. Same as Figure 4, but for $[\mathrm{B}]_{0}=(0,0.5,0.7,1.0) 1 \%$, for curves $(1,2,3,4)$; for $\left[\mathrm{O}_{2}\right]_{0}=1.0 \mathrm{mg} / \mathrm{L}$ (left Figure) and $\left[\mathrm{O}_{2}\right]_{0}=4.0 \mathrm{mg} / \mathrm{L}$ (right Figure),
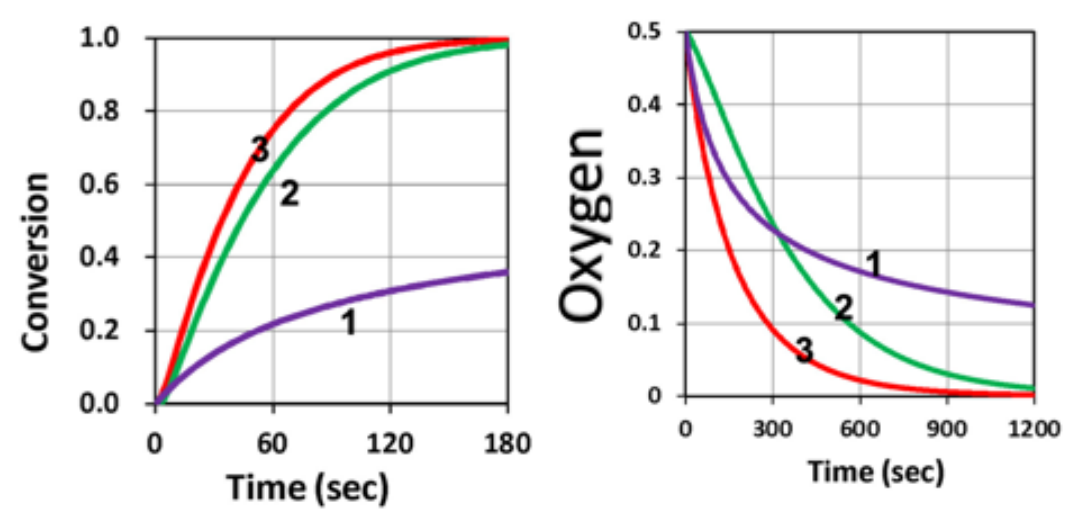

Figure 6. Conversion profiles (left) and oxygen concentration (right), under irradiation of UV-only (curve-1), blue-only (curve-2), and both UV and blue (curve-3); for a fixed $\left[\mathrm{O}_{2}\right]_{0}=0.5 \mathrm{mg} / \mathrm{L}$.
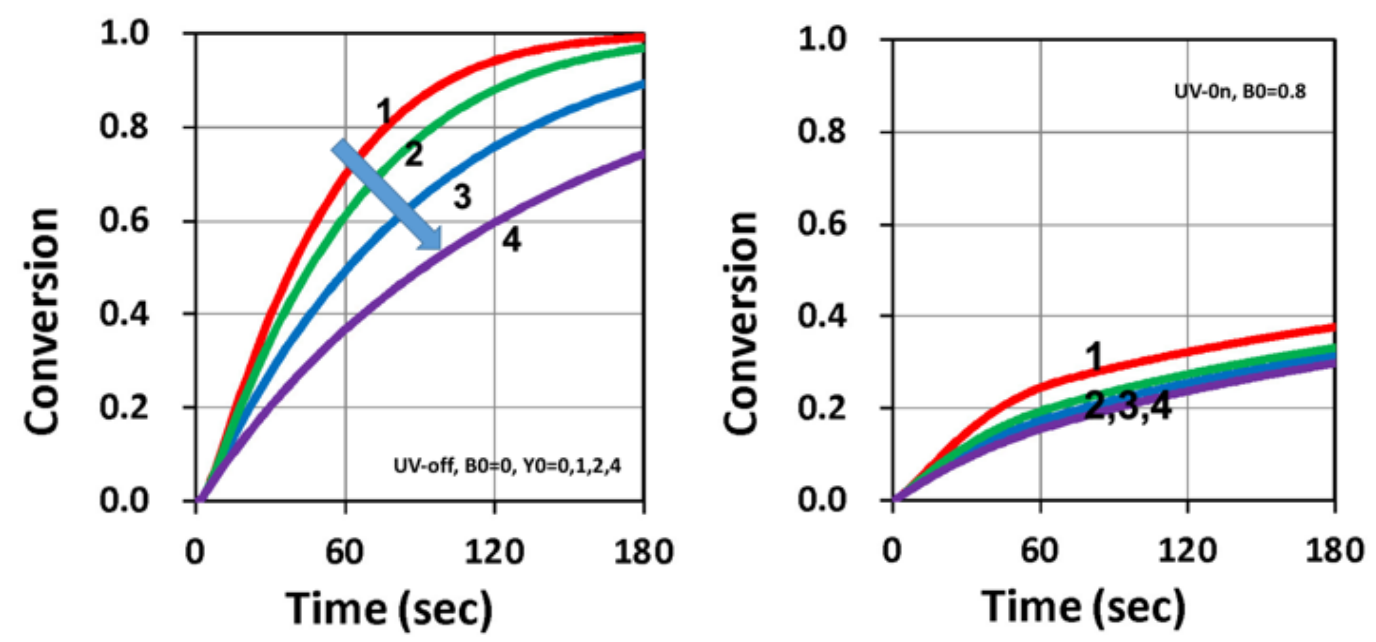

Figure 7. Conversion profiles under the irradiation of: (left) 2-light (blue and red); and (right) 3-light (blue, red and UV), for various initial oxygen concentration of $\left[\mathrm{O}_{2}\right]_{0}=(0,1.0,2.0,4.0) \mathrm{mg} / \mathrm{L}$, for curve $(1,2,3,4)$; with $[\mathrm{A}]_{0}=1 \%$, $[\mathrm{B}]_{0}=0.8 \%,[\mathrm{C}]_{0}=1 \%$. 

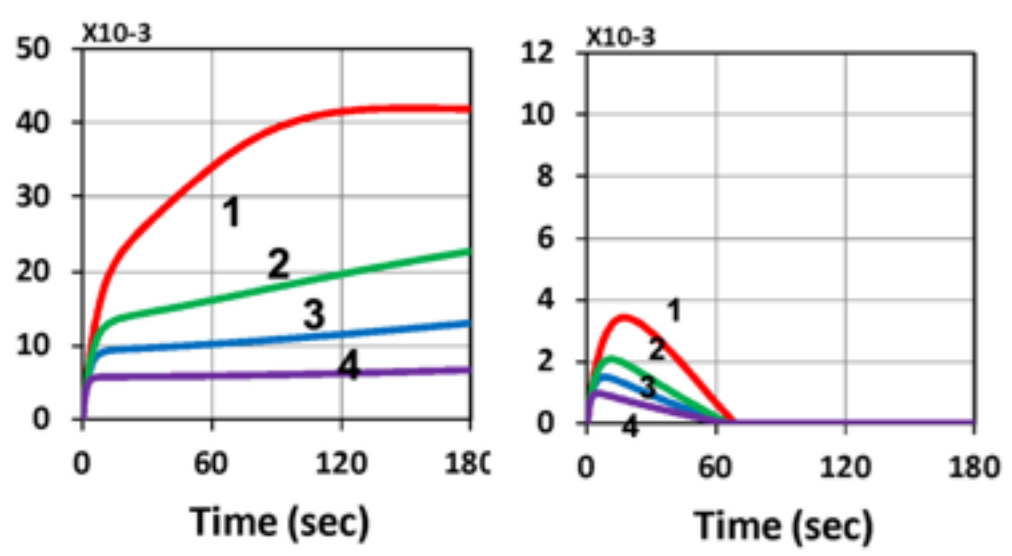

Figure 8. Conversion profiles under the irradiation of: (left) 2-light (blue and red); and (right) 3-light (blue, red and UV), for various initial oxygen concentration of $\left[\mathrm{O}_{2}\right]_{0}=(0,1.0,2.0,4.0) \mathrm{mg} / \mathrm{L}$, for curve $(1,2,3,4)$; with $[\mathrm{A}]_{0}=1 \%,[\mathrm{~B}]_{0}=0.8 \%,[\mathrm{C}]_{0}=1 \%$.
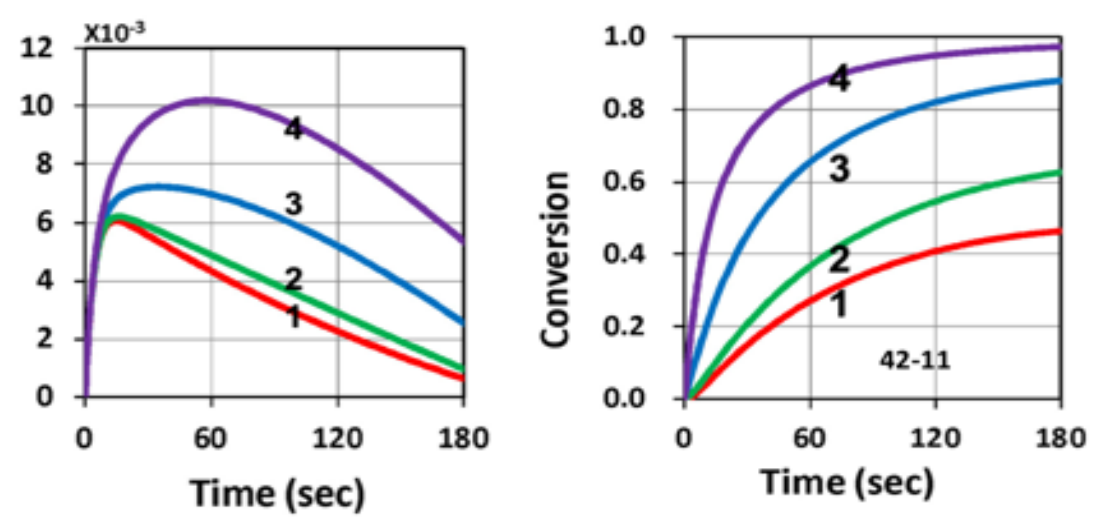

Figure 9. Free radical (left) and conversion profiles (right) under the irradiation of 3-light (red, blue and UV), for various initial concentration of $[\mathrm{C}]_{0}=(0,1.0,2.0,3.0) 1 \%$, and $[\mathrm{A}]_{0}=1.0 \%,[\mathrm{~B}]_{0}=0.5 \%$, $\left[\mathrm{O}_{2}\right]_{0}$ $=1.0 \%$.

\subsection{Efficient $U V$-inhibiton}

The monomer-dependence of a dual-wavelength PC was reported by van der Laan et al [11], in which different monomers have different $\mathrm{C}=\mathrm{C}$ bond rate constants $(\mathrm{K})$ under the exposure of blue, $\mathrm{UV}$ and blue+UV. For example, bisphenol ethoxylate diacrylate (BPAEDA) resins formulated with camphorquinone (CQ) and ethyl 4-(dimethylamino)benzoate (EDAB) have a maximum conversion rate constant $\mathrm{Kmax}=0.675$ (at blue+UV) for $0 \%$ butyl nitrite $(\mathrm{BN})$, and reduces to 0.0106 (for $1 \% \mathrm{BN}$ ), a factor of 64 reduction, Therefore, it is a better candidate than trimethylolpropane triacrylate (TMPTA) which only has a 3 times reduction of Kmax. The above measured feature could be mathematically described by a more general criterion.

Based on our H-factor defined in Eq. (20), and shown by Figure 4 (right Figure), a general criterion for efficient UV-inhibitor, or a good PC candidate, could be mathematically determined as follows. Defining two H factors: Hoff and Hon for the H-value without and with UV-inhibition, respectively. Therefore, $\mathrm{H}=\mathrm{H}=\mathrm{gDB} 1[\mathrm{~A}]-\mathrm{B}_{2}[\mathrm{~B}]=\mathrm{HofF}-\mathrm{HoN}=\mathrm{Hoff}\left(1-\mathrm{RH}_{\mathrm{H}}\right.$, with an H-ratio, $\mathrm{R}_{\mathrm{H}}=\mathrm{HoN}_{\mathrm{H}} / \mathrm{HofF}$. Therefore, a good candidate requires two conditions: (i) a large Hoff (with conversion $>60 \%$ ), with $\mathrm{HON}_{\mathrm{O}}=0$; and (ii) a small $\mathrm{H}$ (with conversion $<20 \%$, with $\mathrm{HoN}>0$ ), i.e., $\mathrm{R}_{\mathrm{H}}$ closes to one. For example, for a given value of $\mathrm{HoFF}_{2}=5$, a candidate with $\mathrm{HoN}_{2}=2$, leading to $\mathrm{R}_{\mathrm{H}}=0.4$, and $\mathrm{H}=5 \times(1-0.4)=3.0$, is not as 
good as a candidate having a higher $\mathrm{HoN}_{\mathrm{N}}=4$, leading to $\mathrm{R}_{\mathrm{H}}=0.8$ and $\mathrm{H}=1.0$, which is 4 times lower, presenting a strong inhibition (or more effective $\mathrm{PC}$ ) after the UV-light.

In the H-ratio, $\mathrm{R}_{\mathrm{H}}=\mathrm{B}_{2}[\mathrm{~B}] /\left(\mathrm{gDB} \mathrm{B}_{1}[\mathrm{~A}]\right)$, we note that $\mathrm{B}_{\mathrm{j}}=\mathrm{b}_{\mathrm{j}} \mathrm{I}_{\mathrm{j}}$, which is proportional to the light intensities ( $\mathrm{I}_{1}$ for blue-light and and $\mathrm{I}_{2}$ for UV-light) and the effective absorption constant $\left(\mathrm{b}_{\mathrm{j}}\right)$ governed by the quantum yield (q) and absorption coefficient at a specific wavelength. Therefore, the H-ratio $\left(\mathrm{R}_{\mathrm{H}}\right)$ is determined not only by the material properties, but also the ratio of light intensity (UV/blue), and concentration ratio of the initiator and inhibitor, $\mathrm{C}_{20} / \mathrm{C}_{10}$. In addition, it is also rateconstant (or monomer) dependence, because the g-factor is given by $g=g=1 /\left(k_{57}+k C_{3}\right)$. Therefore, we conclude that the criterion for a good candidate is governed by collective factors, and at least by the double ratio of $\left[\mathrm{I}_{20} \mathrm{C}_{20}\right] /\left[\mathrm{I}_{10} \mathrm{C}_{10}\right]$. Above criterion is the important new finding of our theoretical study, which requires further experimental study to confirm.

\subsection{Discussion of general features}

From the numerical results and our analytic formulas, we are able to summarize the following important features and new findings.

(i) An effective PC requires two conditions: (i) a strong N-inhibition for uncured regime with a low conversion (triggered by the UV-light); and (ii) a weak S-inhibition (oxygen-induced) for high conversion under the blue-light or blue and red-light initiation. As shown by Figure 4, the N-inhibition is an increasing function of the inhibitor concentration, [B]. However, it is also limited by a transition value defined by $\mathrm{H}=0$, which leads to $\mathrm{R}=0$, as shown by Eq. (19),

(ii) A reverse feature (as shown by the dashed-curve of Figure 4) is found when [B] is higher than the transition value, and thus leads to a higher conversion, resulted from the first term of the total rate $\mathrm{R}_{\mathrm{T}}$, as predicted by our analytic formula, Eq. (16), (19) and (37). This is one of the new findings of this modeling study, which, however, requires further experimental justification.

(iii) Good material candidates for effective PC is governed by an $\mathrm{H}$-ratio, $\mathrm{R}_{\mathrm{H}}$, and requires two conditions: (i) a large Hoff (with conversion $>60 \%$ ), with Hon=0; and (ii) a small $\mathrm{H}$ (with conversion $<20 \%$, with $\mathrm{HoN}_{\mathrm{N}}>0$ ), i.e., $\mathrm{R}_{\mathrm{H}}$ closes to one. A good candidate is governed by collective factors of: (i) the double ratio of light-intensity and initiator-concentration, $\left[\mathrm{I}_{20} \mathrm{C}_{20}\right] /\left[\mathrm{I}_{10} \mathrm{C}_{10}\right]$, (ii) monomers rate-constant; and (iii) effective absorption constants at specific wavelength and initiators. For example, ethyl 4-(dimethylamino)benzoate (EDAB) was reported to be a better candidate than trimethylolpropane triacrylate (TMPTA), which has a smaller RH than that of EDAB [11].

(iv) As shown by Figure 2, higher oxygen concentration leads to a lower conversion, which could be enhanced by reducing the S-inhibition via a red or blue-light preirradiation based on the oxygen profiles shown by Figure 2, For example, to obtain a reduced oxygen concentration of $1.0 \mathrm{mg} / \mathrm{L}$ (form an initial value of $2.0 \mathrm{mg} / \mathrm{L}$ ), the preirradiation time $\mathrm{T}_{\mathrm{P}}=200$ s, when only red-light is used (left Figure 3), and reduces to $150 \mathrm{~s}$, when both red and bluelight are used (right Figure 3).

(v) As shown by Figure 6, UV-only leads to the lowest conversion, lower than the blue-only. Conversion could be improved by the dual-light (blue and UV), and further enhanced by the preirradiation of red-light.

(vi) The role of oxygen is shown in Figure 7, where higher initial oxygen concentration $\left[\mathrm{O}_{20}\right]$ and/or red-light sensitizer concentration of $[\mathrm{C}]$ o lead to a lower conversion. as also predicted by Eq. (37).

(vii) The two competing factors, $\mathrm{N}$-inhibition and S-inhibition, could be independently and selectively tailored to achieve: (a) high conversion of blue-light (without UV-light), enhanced by red-light preirradiation for minimal S-inhibition; and (b) efficient PC initiated by UV-light produced N-inhibition for reduced confinement thickness for high print speed.

\subsection{Suggested Experiments}


The theory (formulas) developed in this study could be further explored/justified by the following with the suggested experiments.

(i) Our proposed double ratio $\left[\mathrm{I}_{20} \mathrm{C}_{20}\right] /\left[\mathrm{I}_{10} \mathrm{C}_{10}\right]$ criterion could be experimentally justified by an experimental setup having adjustable light intensities and the initiator concentrations. The experimental setup of Childress et al. [12], using various light red and UV light intensity ( $\mathrm{I}_{10}$ and $\mathrm{I}_{20}$ ), but fixed concentrations of $\mathrm{C}_{10}$ and $\mathrm{C}_{20}$, could be easily extended for variable concentrations, such that our double ratio criterion could be justified. In addition, various materials may be used to test the monomer-dependence of our H-ratio.

(ii) The dual-wavelength setup of de Beer et al [10] and van der Laan et al [11] could be extended to include a third red-light to reduce the oxygen inhibition by red-light pre-irradiation, specially for thin film cases, where PC efficacy and printing speeds could be measured to justify our proposed strategies..

\section{Conclusion}

We have presented the detailed kinetics for a 3-wavelength PC system, in which both numerical solutions and analytic formulas are explored. The dynamic profiles are simulated for oxygen, free radical, and conversion for various situations of: blue-light only, 2-light (red and UV), and 3-light (red, blue, UV). An effective PC requires two conditions: (i) a strong $\mathrm{N}$-inhibition for uncured regime having a low conversion (triggered by the UV-light); and (ii) a weak S-inhibition (oxygen-induced) for high conversion under the blue-light or blue and red-light initiation. Good PC candidates are governed by a criterion defined by collective factors of: (i) the double ratio of light-intensity and initiator-concentration, (ii) monomers rate-constants; and (iii) effective absorption constants at specific wavelength and initiators. Higher oxygen concentration leads to a lower conversion, which could be enhanced by reducing the S-inhibition via a red or blue-light pre-irradiation. The strategy for an efficient PC could be achieved by tailoring the two competing factors, N-inhibition and Sinhibition, independently via the steps of: (i) red-light pre-irradiation for minimal S-inhibition (oxygen-inhibition); and (ii) followed by a combined irradiation of UV and blue light, under the criterion for efficient PC to achieve reduced confinement depth, and high print speed.

Author Contributions: Conceptualization, Jui-Teng Lin; Data curation, Hsia-Wei Liu and Kuo-Ti Chen; Formal analysis, Jui-Teng Lin and Hsia-Wei Liu; Funding acquisition, Hsia-Wei Liu and Yin-Chen Chiu; Investigation, Hsia-Wei Liu, Yin-Chen Chiu and Da-Chuan Cheng; Methodology, Jui-Teng Lin; Project administration, HsiaWei Liu; Software, Kuo-Ti Chen; Supervision, Jui-Teng Lin and Hsia-Wei Liu; Validation, Hsia-Wei Liu, YinChen Chiu and Jui-Teng Lin; Writing - original draft, Jui-Teng Lin; Writing - review \& editing, Jui-Teng Lin and Hsia-Wei Liu.

Funding: Author DC Cheng thanks the financial support from China Medical University (CMU) under grant number CMU 108-S-25.

Conflicts of Interest: Jui-Teng Lin is the CEO of New Vision, Inc. The funders had no role in the design of the study; in the collection, analyses, or interpretation of data; in the writing of the manuscript, or in the decision to publish the results.

\section{References}

1. Belter, J.T.; Dollar, A. M. Strengthening of 3D printed fused deposition manufactured parts using the fill compositing technique. PLOS ONE 10, 2015, e0122915.

2. Gao, G.; Zhang, Y.; Ramanujan, D.; Ramani, K.; et al. The status, challenges, and future of additive manufacturing in engineering. Comput. Aided Des. 2015, 69, 65-89.

3. Ligon, S. C.; Liska, R.; Stampfl, J.; Gurr, M.; Mulhaupt, R. Polymers for 3D Printing and Customized Additive Manufacturing. Chem. Rev. 2017, 117, 10212-10290.

4. Takagishi, K.; Umezu, S. Development of the improving process for the 3D printed structure. Sci. Rep. 2017, 7,39852 .

5. Shusteff, M.; Browar, A. E. M.; Kelly, B. E.; Henriksson, J.; Weisgraber, T. H.; Panas, R. M.; Fang, N. X.; Spadaccini, C. M. One-step Volumetric Additive Manufacturing of Complex Polymer Structures. Sci. Adv. $2017,3,7$. 
6. Janusziewicz, R.; Tumbleston, J. R.; Quintanilla, A. L.; Mecham, S. J.; DeSimone, J. M. Layerless Fabrication with Continuous Liquid Interface Production. Proc. Natl. Acad. Sci. U. S. A. 2016, 113, 11703- 11708.

7. Zhu, W.; Tringale, K. R.; Woller, S. A.; You, S. T.; Johnson, S.; Shen, H. X.; Schimelman, J.; Whitney, M.; Steinauer, J.; Xu, W. Z.; Yaksh, T. L.; Nguyen, Q. T.; Chen, S. C. Rapid Continuous 3D Printing of Customizable Peripheral Nerve Guidance Conduits. Mater. Today 2018, 21, 951-959.

8. Kelly, B. E.; Bhattacharya, I.; Heidari, H.; Shusteff, M.; Spadaccini, C. M.; Taylor, H. K. Volumetric Additive Manufacturing via Tomographic Reconstruction. Science 2019, 363, 1075-1079.

9. Scott, T. F.; Kowalski, B. A.; Sullivan, A. C.; Bowman, C. N.; McLeod, R. R. Two-Color Single-Photon Photoinitiation and Photoinhibition for Subdiffraction Photolithography. Science 2009, 324, 913-917.

10. de Beer, M. P.; van der Laan, H. L.; Cole, M. A.; Whelan, R. J.; Burns, M. A.; Scott, T. F. Rapid, Continuous Additive Manufacturing by Volumetric Polymerization Inhibition Patterning. Sci. Adv. 2019, 5, 8.

11. van der Laan, H. L.; Burns, M. A.; Scott, T. F. Volumetric Photopolymerization Confinement through DualWavelength Photoinitiation and Photoinhibition. ACS Macro Lett. 2019, 8, 899-904.

12. Childress, K.K.; Kim, K.; Glugla, D.J.; Musgrave, C.B.; Bowman, C.N.; Stansbury, J.W. Independent control of singlet oxygen and radical generation via Irradiation of a two-color photosensitive molecule. Macromolecules 2019, 52, 4968-4978.

13. Lin, J.T. Efficacy S-formula and kinetics of oxygen-mediated (type-II) and non-oxygen-mediated (type-I) corneal cross-linking. Ophthalmology Research. 2018, 8,1-11.

14. Lin, J.T.; Cheng, D.C. Modeling the efficacy profiles of UV-light activated corneal collagen crosslinking. PloS ONE. 2017, 12, e0175002.

15. Lin, J.T. Kinetics of enhancement for corneal cross-linking: proposed model for a two-initiator system. Ophthalmology Research. 2019, 10:1-6.

16. Chen KT, Lin JT, HW Liu. Enhancing radical-mediated photopolymerization efficacy and crosslink depth: kinetic and model of a two-monomer system. Res Med Eng Sci. 2019, 8(2):853-860.

17. Lin, J.T.; Cheng, DC; Chen, K.T.; Liu, H.W.; Dual-wavelength (UV and Blue) controlled photopolymerization confinement for 3D-printing: modeling and analysis of measurements. Polymers. 2019, 11, XX

18. Alvankarian, J.; Majlis, B.Y. Exploiting the oxygen Inhibitory effect on UV curing in microfabrication: A modified lithography technique. PLoS ONE 2015, 10, e0119658. doi:10.1371/journal. pone.0119658.

19. Chen, F.H.; Pathreeker, S.B.; Hosein, I.D. Synthesis of micropillar arrays via photopolymerization: An in Situ study of light-induced formation, growth kinetics, and the influence of oxygen inhibition. Macromolecules 2017, 50, 5767-5778.

20. Wu, J.; Zhao, Z.; Hamel, C.M.; Mu, X.; Kuang, X.; Guo, Z.; Qi, H.J. Evolution of material properties during free radical photopolymerization. J. Mech. Phys. Solids 2018, 112, 25-49.

21. Egan, P.F. Integrated design approaches for 3D printed tissue scaffolds: Review and outlook. Materials 2019, 12, 2355. 